\title{
NOTES ON BOOKS
}

Popular Education in Public Health, by W. Allan Daley, M.D., B.Sc. (Lond.), and P.H. (Camb.), and Hester Viney, S.R.N. (6s.). The authors deserve a word of praise for their conjoint effort. For those who are really interested in the Health Education movement this volume supplies a long-felt want. Health in the home, in the school, at the various clinics connected with Child Welfare, Tuberculosis, Venereal Diseases are considered, and Birth Control is discussed in a very rational manner. Hints to those who desire to conduct classes and to teach public health are admirably treated.

In Outwitting Middle Age Dr Carl Ramus (George Allen \& Unwin, price 7s. 6d.) approaches the much discussed subject of "anno domini" as a confirmed optimist. His book is written sufficiently from a scientific standpoint to be exact, yet anecdotal enough to make extremely interesting and entertaining reading for all. It is a book out of the common run that can thoroughly be recommended as of general interest.

Outlines of Dental Science. First five volumes (E. \& S. Livingstone, 7s. 6d. each volume) :-

Dental Ancesthesia is treated by G. F. Rawdon Smith, who gives an account of the methods he has found useful in Liverpool.

its pur. A. Broderick has written a little manual which admirably fulfils logirpose $-a$ succinct presentation of first principles and of bacteriological technique.

the Dental Materia Medica has been entrusted to Mr P. H. Marsden, given under on that subject in Liverpool University. Blood serum is by the under Hæmostatics, but all the student is told is that it is given increase mouth "for the treatment of duodenal ulcers, and that to back or the soft parts of the body as the abdomen." Eusol is
mentioned but able for but the formula is not given. The book is more remarkfor what it omits than for what it includes.

laboratary Prosthetics, by J. Douglas Logan, deals with dental be helpful practice clearly and briefly; much of the instruction should helpful to the student.

\footnotetext{
Dental Radiography, by Charles A. Clark, is an excellent introduction to the practice of that art. It describes the apparatus and methods in an exact and lucid manner. The chapter on interpretation is good and the book is well illustrated.
} 


\section{Notes on Books}

Dental Prosthetic Mechanics, by D. M. Shaw (Arnold, $2 \mathrm{rs}$.), has been written by a skilled and experienced craftsman, who can describe, justify, and defend the methods he prefers and has for long taught. The various procedures are fully treated and well illustrated. The author has given us a careful exposition of the principles and practice of dental art applied to the designing and construction of dentures on vulcanite or gold base-plates, which should be a valuable guide, not only to the student, but to the practitioner. The man who masters the contents of this book, and can perform all the instructional exercises and examination tests it provides, will be well grounded in Dental Prosthetic Mechanics.

Surgical Applied Anatomy, by Sir Frederick Treves (Cassell), $\mathrm{Mr}$ Choyce is to be congratulated on the manner in which he has revised the eighth edition of this well-known Manual. He has brought every section well abreast of modern teaching without in any way altering the atmosphere originally imparted by Treves.

Diseases of the Heart and Lungs, by A. I. G. McLaughlin, M.B., Ch.M. (Syd.) (Faber \& Gwyer, price 4s. 6d.). This admirable book, written for the use of nurses, could be used to advantage by students, and would facilitate greatly subsequent reading of larger works. It includes all the main features of diseases of heart and lungs, together with descriptions of the later methods of investigation.

Physical Therapy in Diseases of the Ear, Nose, and Throat, by A. R. Hollender, M.D., and M. H. Cottle, M.D. (Churchhill, 2 Is.). Electro-physical therapy is being more and more appreciated and the authors have clearly set out its application to diseases of the Eye, Ear, Nose, and Throat. The volume is an earnest attempt to systematise and classify the available material and to invite attention to the unlimited therapeutic possibilities in ophthalmology and in oto-rhinolaryngology. The authors are to be congratulated on not laying down any hard or fast rules, but merely showing how the use of physical agents, properly applied, may save both time and energy.

The Natural Processes of Healing in Pulmonary Tuberculosis, by Marc Jaquerod, M.D., translated by J. Denny Sinclair, M.B., Ch.B. (Bailliere, 6s.). The author presents a short account of the healing of pulmonary tuberculous lesions by resolution, by fibrous transformation, by cavity formation, by pulmonary retraction and displacement of the mediastinum, and by calcification, illustrated by notes, diagrams, and X-ray photographs of thirty-five cases. Special emphasis is laid upon the process of resolution (a possibility which is not generally recognised), and the need for early and prolonged treatment, to attain this result, is insisted upon. 


\section{Notes on Books}

Materia Medica and Therapeutics, by Mitchell Bruce and Dilling (Cassell, ros. 6d.). The most recent thirteenth edition of this well-known students' text-book brings the subject-matter well up to date. It includes a succinct account of Vaccine therapy and Insulin, and the volume adequately fulfils its function as a reliable text-book for students preparing for their professional examination.

Text-book of Midwifery, by R. W. Johnstone, C.B.E., M.D., F.R.C.S.E., fifth edition (A. and C. Black, price r 5s.). Professor Johnstone derives great credit from the fact that though his wellknown text-book has passed through five editions, there has only been an addition of twenty pages to the text, and thus the compact nature of the book, so popular with students, is adhered to. To accomplish this, a certain amount of judicious pruning has been carried out, so that all important advances in the subject could be included without enlarging the book unduly.

Practical Physiological Chemistry, by Philip B. Hawk, M.S., Ph.D., President of the Food Research Laboratories, Inc., New York City, and Olaf Bergeim, M.S., Ph.D. (Churchill, price $28 \mathrm{~s}$.). The ninth edition of this standard manual on Physiological Chemistry represents an unusually thorough overhaul and revision, and special trouble has been taken to secure new illustrations. In virtue of special help in the present and previous editions, the name of Professor Bergeim now appears on the title-page. The present edition more than maintains the high reputation of the book in giving a comprehensive and standard survey of the chemistry of the body.

Diseases of the Eye, by Sir John Parsons (Churchill, price Igs.).
Parsons' companion thook on Diseases of the Eye has always proved a useful is the Chief same familiar friend with but few alterations and additions. of the the additions is a very brief description of the microscopy allusions living eye by use of the slit lamp, and some even more brief which are th throughout the text. Also there are a few new drawings which are always helpful, and the whole text has again been revised.

is Pernicious Anamia, by Frank A. Evans, M.D. (Baillière, Irs. 6d.), if not representatics from the Johns Hopkins Hospital, on a limited assertion. of the disease Chapter II., from the first source, deals with the occurrence statements disease and is of value. We are at variance with most of the the advice to give the blood on page 99. We cannot support gastro-intesting give hydrochloric acid as a routine whether there are not tolerate hylinal symptoms or not. Some cases do well, but many do 


\section{Notes on Books}

Physiology and Bio-Chemistry in Modern Medicine, by J. J. R. Macleod, M.B., LL.D., and others, fifth edition (Kimpton, I926, $42 \mathrm{~s}$.). "While still retaining the original purpose to serve as a guide to the application to the truths of physiology in the bedside study of disease, this manual has been expanded in order that it may also be used as a text-book of physiology for students of medicine" (Preface). We doubt the complete success of this double intention. Clinician and student alike will be inclined to think that the other party gets more than his share. The excellencies of the book are, of course, well known. The chapters on the heart, respiration, and metabolism are of great value.

In The Meaning of Disease, Dr William A. White, A.M., M.D. (Williams \& Wilkins, I3s. 6d.), conducts a philosophical inquiry into the mental processes which are employed in medical science. It is a psychological study and analysis of the thought-processes and thought-symbols (language) employed by practitioners and scientific investigators in medicine. It may be described as a plea for a larger view of disease. Disease is too apt to be considered as an entity, but yet it is never more than a partial expression of disordered vital activity. Disease and health are indeed only different phases of life.

Manipulative Surgery, by A. G. Timbrell Fisher, M.C., F.R.C.S. (H. K. Lewis, 7s. 6d.) emphasises the value of manipulative procedures in the treatment, in carefully selected cases, of certain sequele of injury and disease of the joints, muscles, fascix and tendons-a class of case which has attracted much attention during recent years. The anatomy, physiology and pathology of the articulations with reference to the prevention and cure of adhesions are described and illustrated in novel and arresting fashion. Each joint is then considered seriatim and the technical details of manipulation demonstrated. The section on the knee is most instructive. The dangers of misapplied manipula. tion are emphasised. The final chapter is devoted to the details of aftertreatment, so important in injury and internal derangements of joints.

Manual of Hygiene and Public Health, by Jahar Lal Das, D.P.H. (Butterworth, ros. 6d.), is a valuable compendium of information; comprehensive, clearly expressed, and well arranged. The author's admirable handling of various subjects with up-to-date Western thoroughness and intimate knowledge of Eastern conditions is perhaps nowhere more happy than in his account of cholera, which vividly recalls memories of India. It is a manual which might be perused with advantage by many a candidate on the eve of presenting himself for his D.P.H. examination; few recent text-books contain so much information in so small a compass. 


\section{Notes on Books}

In Applied Physiology, by Samson Wright, M.D., M.R.C.P. (Milford, I5s.), we have a book written by a competent physiologist which should appeal to the scientific practitioner. In short compass it is a mine of information not readily available in other form. There is, however, no attempt at orderly arrangement. At the outset we are plunged into an account of cerebro-spinal fluid and the heading, anatomy, means distribution. Cross references and a good index, however, provide compensation.

The Transactions of the American Association of Genito-Urinary Surgeons, Vol. xviii. (Williams \& Wilkins Company), incorporate the Several papers read at the $37^{\text {th }}$ Annual Meeting of the Association, held in May 1925 ; the subjects include extroversion of the bladder through the female urethra, congenital stricture of the ureter, and special methods of intravenous therapy in infective conditions of the urinary tract.

The object of a book on applied anatomy, is to present the facts of surgery and medicine on an anatomical basis, without the minute and tedious detail of the anatomical text-book. Davis' Applied Anatomy, revised by George P. Muller, M.D. (Lippincott, 42s.) achieves this object admirably. The present (seventh) edition includes details on the sympathetic nervous system, thyroidectomy, lymphaticostomy and several other recent surgical procedures. The illustrations are excellent and illuminating. If any criticism is justified, it is of a tendency to devote too much space to the rarer at the expense of the more common conditions, e.g., the operation for the removal of the spheno-palatine (Meckel's) ganglion is fully described, while the deep palmar spaces of the hand receive no mention.

The third edition of Microbiology by W. Giltner (Chapman and The , maintains the character and practical value of earlier editions. carefully is entirely a laboratory guide and comprises a large series of biology. planned laboratory exercises for students of general microfield, ing. In this respect it is fairly comprehensive and covers a wide various hyding the applications of bacteriology to agriculture and practical studic applications. The book is admirably suited for the of little study of bacteriology as a purely biological science, though little direct utility for purposes of medical study.

M.D., fourth edition of Treatment of Diabetes Mellitus, by O. Leyton, account of., F.R.C.P. (Aldard, 6s.), gives a brief and up-to-date interesting the treatment of diabetes. The book contains some in relation discussions regarding infections and the use of anæsthetics practition to diabetes. It contains much useful information for practitioners, but is not suited for perusal by patients. 